\title{
TRABALHO E EDUCAÇÃO POLITÉCNICA: ELEMENTOS DA EXPERIÊNCIA EM EDUCAÇÃO DO MOVIMENTO DOS TRABALHADORES RURAIS SEM TERRA
}

\author{
Work and polytechnic education: Elements of experience in education of landless rural \\ workers' movement
}

Maria Izabel Grein

Especialista em Educação do Campo; Membro do Setor de Educação do MST

maigrein@gmail.com

Artigo recebido em 28/01/2013 e aceito para publicação em 10/04/2013

DOI: 10.12957/tamoios.2013.8079

RESUMO Neste artigo buscamos compreender a prática e a proposta de educação do MST que traz em uma de suas matrizes pedagógicas, o princípio educativo do trabalho e que na sua concretização se aproxima da educação politécnica, defendida por Marx, revista por Gramsci na Escola Unitária e experimentada dentro de seus limites pelo Movimento dos Trabalhadores Rurais Sem Terra. O ser humano se constitui como humano intervindo na natureza para resolver as suas necessidades e na medida em que vai criando ferramentas e aperfeiçoando sua intervenção modifica a natureza e se modifica a si mesmo, inclusive nos seu físico, no seu corpo, e desenvolvendo todas as suas possibilidades humanas (de criar, de projetar, produzir, intervir, modificar, transformar...) e ao mesmo tempo vai desenvolvendo outras relações e criando cultura e a vida em sociedade. $\mathrm{O}$ trabalho alienado pelo capital cria a monstruosidade, mas ao mesmo tempo não consegue tirar a capacidade humana de revolucionar esta situação, por isso é possível pensar uma educação da classe trabalhadora que contribua para o avanço de sua consciência de classe e de humanidade resgatada.

Palavras chave: Trabalho; Politecnia; Escola; Humanização.

ABSTRACT This article aims to understand the practice and education proposal that MST brings in one of his pedagogical bases, the educational principle of work and their implementation approaches polytechnic education defended by Marx , Gramsci reviewed by the Unitarian School and experienced within its limits by the Rural Landless Workers Movement . humans consolidates itself interfering with nature to solve their needs and to the extent that will create tools and perfecting his intervention modifies the nature and changes yourself, even in your physical, your body, and developing all their human possibilities ( to create, to design, produce, act, edit, transform ... ) while others will develop relationships and creating culture and life in society. The alienated labor by capital creates the monstrosity, but at the same time can not take the human capacity to revolutionize this situation, so it is possible to think an education of the working class that contributes to the advancement of their class consciousness and redeemed humanity.

Keywords : Job ; Polytechnic ; School; Humanization 
É possível desenvolver a politecnia nas Escolas do Campo, tendo presente que hoje indústria e campo não estão separados, uma vez que há uma dependência de um espaço com o outro. A indústria está no campo através de sua produção (máquinas, insumos agrícolas) e o campo está na indústria através da matéria prima por ele produzida, pela mão de obra que na sua origem foi produzida no campo, as primeiras gerações de operários datam da última década do século $\mathrm{XX}$, inicio do século XXI, mas mesmo assim o campo continua transferindo mão de obra para a cidade. Por outro lado a agricultura só foi possível com a criação das primeiras tecnologias, mesmo sendo muito rudimentares ainda.

Não podemos esquecer que o campo brasileiro historicamente esteve subordinado aos interesses do capital e ao modelo agroexportador, uma história marcada pela concentração da terra e da riqueza e consequentemente a educação que chegou a estes espaços estava direcionada a estes interesses. E o Movimento Sem Terra ao fazer a luta pela terra logo se defronta com estes interesses e busca uma educação que responda aos seus objetivos, que é uma educação emancipadora e do direito. Podemos afirmar que as experiências em educação que o MST vem fazendo se aproxima de uma formação politécnica? A politecnia pode ser uma alternativa para as Escolas do Campo?

Desde que o MST começou a fazer e a pensar educação o trabalho é uma de suas matrizes pedagógicas, por que para os camponeses o trabalho é algo constitutivo de suas vidas. Ambiente de trabalho e ambiente onde se vive é o mesmo. As crianças se educam brincando com os instrumentos de trabalho dos adultos em miniatura e vão criando ambientes, inventando instrumentos para brincar e com isso desenvolvendo suas capacidades de idear e com o tempo vão executando pequenas tarefas que perpassam o cotidiano do campo.

Com estas observações os educadores vão buscar na ciência o conhecimento de como o ser humano se desenvolve e compreender quem é o ser humano e como se educa. Para Marx, o ser humano nasce em sociedade e se produz e reproduz na história. Tudo o que está na história não é alheio ao ser humano (2009). Portanto o ser humano se faz um humano produzindo a história e organizando a sociedade. E compreende que o "o homem se constitui como tal à medida que necessita produzir continuamente sua própria existência” (Marx apud Saviani, 2003, p.133). Ao contrário dos animais que tem a sua existência garantida pela natureza e apenas se adaptam, o ser humano adapta a natureza a si, por meio do trabalho. Trabalhar nada mais é que, mediado pela energia humana e pelo conhecimento transformado em técnicas e instrumentos de trabalho, agindo sobre a natureza transforma-a, para satisfazer as necessidades.

Podemos então entender que o trabalho é um processo em que participam o homem e a natureza. Com sua ação o homem impulsiona, regula e controla seu intercâmbio material com a natureza. Neste sentido o trabalho é o criador do ser humano, pois ao intervir na natureza para satisfazer as suas necessidades vai se modificando tanto no seu físico, no seu corpo, como na capacidade de idear, de pensar, de propor, de antecipar soluções para os problemas, de se organizar em sociedade. "Atuando assim sobre a natureza externa e modificando-a, ao mesmo tempo modifica sua própria natureza" (MARX, 2011, p.211).

A humanidade, ao desenvolver as primeiras ferramentas ainda que muito rudimentares, teve a necessidade de se comunicar com os outros seres humanos, por conta disso também o seu organismo se modificou. A constituição da linguagem é um exemplo bastante ilustrativo, com a necessidade de se comunicar gerado pela descoberta das primeiras ferramentas (o osso, a pedra, a força do braço), de grunhidos, com o aperfeiçoamento das cordas vocais, o ser humano passou a articular sons até chegar à linguagem que conhecemos. Todo o seu corpo foi se modificando, seu cérebro fazendo novas conexões, e assim foi desenvolvendo a sociabilidade. 
Em nossa sociedade as pessoas têm em seu corpo, em sua mente, no seu jeito de ver o mundo e de viver, as marcas da profissão que exerce e da classe a qual faz parte, ou seja, o ser humano continua sendo moldado pelo trabalho. Frigotto (2005) diz mais, ao transformar a natureza pelo trabalho, o ser humano não só transforma a si mesmo, mas também a atividade prática é a fonte do conhecimento, da cultura e da conscientização.

Sendo um ser da natureza, mas também da sociedade e da cultura de seu tempo, o ser humano se produz e reproduz pelo trabalho e este como direito e dever, segundo (Frigotto 2012, p.749) "para não ser como pessoas que se comportem como mamíferos de luxo, que acham natural viver explorando o trabalho dos outros" (Apud, Frigotto 2012, p.749)". Neste sentido podemos compreender o trabalho como ação humanizadora, mediante o desenvolvimento de todas as potencialidades do ser humano. Só é possível compreender o trabalho como princípio educativo dentro da análise teórica do materialismo histórico, de que o trabalho é o produtor da vida humana tanto nos aspectos materiais como culturais, sociais, de conhecimento e as formas simbólicas de vida.

$\mathrm{O}$ ser humano, pelo trabalho explicita o objeto que nas suas partes era apenas possibilidade. $\mathrm{O}$ humano antecipa na sua mente o que vai realizar algo que os animais não conseguem fazer. Marx (2011) distingue o pior arquiteto da mais hábil das abelhas.

Uma aranha executa operações semelhantes às do tecelão, e a abelha supera mais de um arquiteto ao construir sua colmeia. Mas o que distingue o pior arquiteto da melhor abelha é que ele figura na mente sua construção antes de transformá-la em realidade. (MARX, 2011, p. 211).

O ser humano precisa aprender a produzir a sua existência, isto nos leva a entender que a produção do homem é também a sua formação, ou seja, é pelo trabalho que vai produzindo as condições de sua sobrevivência e criando existência. E para se produzir e reproduzir o ser humano vai criando relações sociais, e em cada momento da história, de acordo, com as necessidades de intervir na realidade para produzir a sua existência, o homem, também foi criando o seu jeito de educar. No capitalismo o modelo hegemônico de educação e de escola visa formar o ser humano para responder às necessidades do capital e de sua expansão no mundo, com o princípio do lucro, da acumulação permanente e do consumismo.

Marx (2011) faz a análise do capitalismo e revela como se dá a produção de riquezas e a exploração dos trabalhadores. Analisa as contradições geradas pelo capital na sociedade, e nos seus estudos faz uma crítica ao trabalho alienado, no capitalismo. Com estes estudos ajuda a classe trabalhadora a se descobrir como classe e a lutar pela libertação da sociedade. São as condições objetivas, materiais, ou seja, é na produção material da vida (economia, cultura, leis, relações, tudo o que compõe a vida humana) que o ser humano se faz e se educa.

Lukács apud, Frigotto (2005) entende que o que caracteriza a humanidade é a capacidade de refletir sobre a atividade que realiza. Não atribuiu qualquer hierarquia ao trabalho humano. O trabalho se impõe como momento mais importante da vida humana. O referido autor afirma que o trabalho é a essência do ser humano, enquanto existência social. É o elemento mais importante do "fazimento" do ser humano. $\mathrm{O}$ trabalho pode ser entendido como a primeira forma de ação, de práxis humana.

Marx, em suas obras, em especial em "O Capital: crítica à economia política" faz uma análise apurada de como a sociedade de classes e especialmente como o capitalismo explora a riqueza produzida pelo trabalho de muitos trabalhadores e acumula nas mãos de poucos capitalistas.

O capitalista cuida em que o trabalho se realize de maneira apropriada e em que se apliquem adequadamente os meios de produção, não se desperdiçando matéria prima e poupando-se o instrumental de trabalho, de modo que só se gaste deles o que for imprescindível à execução do trabalho... o produto é propriedade do capitalista, não do produtor imediato, o trabalhador (MARX, 2011, p.219).

"Com a expansão da maquinaria e da divisão do trabalho, o trabalho dos proletários perdeu $\underline{\text { sua autonomia (...) ele se torna um apêndice da máquina” (Marx, 2008, p. 20), não motiva mais o }}$ 
trabalhador e neste estágio do capitalismo não interessa mais nem ao capital este tipo de trabalhador especializado em apenas um aspecto da produção, mas do trabalhador polivalente e aqui entra o debate e a questão da formação deste novo trabalhador. Ao debater sobre a politécnica temos que ter claro o horizonte de nosso debate, a permanência na sociedade do capital ou a transformação da sociedade e a formação do trabalhador revolucionário.

Em seus escritos Marx chama a atenção para a questão da propriedade privada dos meios de produção que gera a sociedade dividida em classes e transforma o trabalho em atividade alienante e degradadora do homem, criadora do homem unilateral. E que tanto avilta o trabalhador (operário) como aquele que usufrui do produzido, este se realiza como ser efêmero, irreal, débil, que considera a realização humana como realização de sua desordem, do seu capricho, das suas ideias arbitrárias e extravagantes:

Em primeiro lugar, deve-se observar o que se manifesta no operário como atividade de expropriação, de alienação, se manifesta no não trabalhador como estado de apropriação, de alienação, e a imoralidade, a monstruosidade, são conjuntamente dos operários e dos capitalistas, e se um poder desumano domina o operário, isso também vale para o capitalista (Manacorda, 2010, p. 86).

Em resumo, capitalistas e trabalhadores são uns e outros, subsumidos pela classe, membros de uma classe e não indivíduos.

Marx, preocupado com a formação do trabalhador, da criança e jovem, por um lado analisa a exploração das crianças nas fábricas, mas por outro está preocupado com a preparação do operário revolucionário. Em "O Manifesto do Partido Comunista" quando trata das medidas que se deveriam tomar nos países conquistados pelos trabalhadores, afirma a necessidade de educação pública, gratuita para todas as crianças. Supressão do trabalho fabril de crianças, tal como praticado hoje. Integração da educação com a produção material. (Marx, 2010, p. 45).

Manacorda (2010) em seus comentários observa a preocupação de Marx que defende o princípio da união do ensino ao trabalho material produtivo, mas reconhece que na fábrica da forma que está organizado o trabalho é negatividade, não elimina a divisão do trabalho e por isso não pode ser espaço para qualquer instrução, somente por uma intervenção política na mesma para eliminar seus aspectos mais alienantes, por isso, a fábrica por si só não tem condições de desenvolver uma função libertadora.

O trabalho produz deformidade, imbecilidade, creticismo no operário, que se torna um objeto estranho e desumano, no qual nenhum dos sentidos existe mais, e que não apenas não mais tem necessidades humanas, mas em que também as necessidades animais cessam, pois tornou-se um ser insensível e sem necessidades (MANACORDA, 2010, p.85).

Marx apud Manacorda (2010) no texto "Instruções aos delegados do I Congresso da Associação Internacional dos Trabalhadores", escrito em 1866, faz uma crítica ao trabalho das crianças na fábrica moderna, mas defende que toda criança deve tornar-se um operário produtivo a partir dos 09 anos, e que todo adulto, segundo as leis da natureza, deve "trabalhar não apenas com o cérebro, mas também com as mãos”. Propõe dividir as crianças para fins de trabalho em três grupos dos 09 aos 12, dos 13 aos 15 e dos 16 e 17 anos - com horários diários de 02, 04 e 06 horas, e acrescenta que o ensino pode começar antes do trabalho (IDEM,2010,p.47). E o ensino socialista abrangeria três aspectos:

Ensino intelectual; Educação física; adestramento tecnológico (...) A união do trabalho produtivo remunerado, ensino intelectual, exercício físico e adestramento politécnico elevará a classe operária acima das classes superiores e médias” ( IDEM, 2010, p .48).

Podemos observar que na proposta de Marx o ensino tecnológico não absorve nem substitui a formação intelectual, bem como os exercícios físicos um e outro abrangendo unilateralmente os 
fundamentos científicos de todos os processos de produção e os aspectos práticos de todos os ofícios, e o cuidado com o corpo. Este ensino é para todas as crianças sem distinção.

Em O Capital, Marx (2011) embora o conteúdo esteja semelhante aos anteriores revela-se um desejo e previsão de luta, a questão do poder político como condição para colocar-se em prática a escola do futuro: a transformação da razão social em poder político e as leis impostas como força do Estado, das instruções, tornam-se, em O Capital, a inevitável conquista do poder político por parte da classe operária, Marx enfatiza um único método para produzir esses homens plenamente desenvolvidos, ou seja, daquele ensino associado ao trabalho produtivo.

A politecnia já na época de Marx, esboçada pelo capital como formação polivalente, significava formar força de trabalho preparada para trabalhar em diferentes frentes para evitar o desemprego. Marx critica esta formação, mas não está preocupado em criar coisas novas, com seu método de conhecer o que já existe e partir da materialidade concreta da vida, estuda esta questão do ponto de vista do proletariado e por isso não nega a formação polivalente (o trabalhador dominar diferentes áreas da produção) oferecida pelo capital, mas agrega elementos da ciência, não basta conhecer é necessário para Marx que o trabalhador domine os fundamentos da ciência que deram origem aquela técnica e as relações que se estabelecem ao usar aquela tecnologia o que representa a ampliação da formação do trabalhador.

Podemos já adiantar que a formação em Marx não se dá apenas pelo e no trabalho, mas: trabalho, ensino, práxis. Práxis aqui entendida não só como ação política, ou como uma prática, mas como toda ação humana.

A partir destas reflexões podemos entender em certa medida, que a politecnia é um tipo de formação da força de trabalho que está posta pelas demandas do próprio desenvolvimento do capital, no atual estágio de desenvolvimento da produção e da indústria o tipo de trabalhador requerido é aquele que tem certa versatilidade, capaz de atuar em diferentes ramos de produção, contemplando assim as exigências do movimento de valorização do capital, que exige força de trabalho qualificada e disponível.

Marx, em sua proposta de politecnia vai além, incorpora no seu conteúdo e pedagogia a formação do trabalhador capaz de revolucionar a sociedade existente e criar uma nova ordem social onde já não haja mais a necessidade das classes sociais. A formação dos trabalhadores não pode ser reduzida a uma mera formação técnica diversificada, desta forma, a educação politécnica de Marx não fica apenas na formação tecnológica, mas abrange os três elementos de sua proposta de educação incorporando as atividades físicas e os conhecimentos das ciências que fundamentam estas tecnologias, só esta formação é capaz de elevar a classe trabalhadora acima das demais classes.

Do ponto de vista burguês a educação polivalente é um meio para preparar força de trabalho capaz de garantir a expansão do capital, sua preocupação com os trabalhadores é no máximo com o desemprego. Para Marx, o ensino politécnico tem a função de garantir aos trabalhadores os fundamentos científicos, teóricos e práticos dos diferentes processos de trabalho. Esse domínio deve vir contra a alienação da atividade do trabalho, embora não seja totalmente suficiente. É unir a atividade intelectual à atividade prática, coisa que a formação dos filhos da burguesia não consegue possibilitar.

A formação politécnica para Marx surge acima de tudo como meio de fortalecimento das classes trabalhadoras no seu processo de formação revolucionária. Já para concepção burguesa, a formação politécnica surge como uma questão meramente instrumental de preparação de mão de obra para a produção, segundo as exigências do processo de acumulação capitalista (SOUZA JUNIOR, 2010, p.83).

Na proposta de Marx o que precisa ser levado em conta é o projeto político, histórico da classe trabalhadora, só este pode fortalecer o processo formativo do proletariado como sujeito social 
potencialmente revolucionário. Com este entendimento vamos analisar a prática e a proposta do Movimento dos Trabalhadores rurais Sem Terra, iniciando por sua proposta de reforma Agrária Popular.

\section{A LUTA PELA REFORMA AGRÁRIA POPULAR E A EDUCAÇÃO NO MST}

A luta do MST pela educação e pela escola é fruto da negação, o próprio Movimento nasce da violenta contradição de classes existente nos Brasil e quando se trata do campo é mais grave ainda. $\mathrm{E}$ a ditadura militar, dos anos 64 à 85, agrava ainda mais esta situação, pois cria as condições para a expansão do capital no campo que se hegemoniza na década de 90, expulsando milhares de camponeses de suas terras.

O MST nasce lutando pela terra, mas logo descobre que tem outros latifúndios a enfrentar e um deles é o da educação e da escola, por isso, na sua proposta de Reforma Agrária Popular reflete os anseios de uma sociedade onde todas as relações terão que ser transformadas, desde aquelas que mexem com a estrutura do sistema que é a propriedade, a estrutura da produção no campo e as relações dos seres humanos com a natureza, com a terra com a vida e com os outros seres humanos.

Isto exige que o camponês, o trabalhador se transforme em sujeito de sua própria história. Que seja capaz de interpretar, agir e transformar a realidade. Que seja capaz de fazer a síntese entre o conhecimento teórico e a prática social, política e econômica na sua realidade.

Isso significa valorizar e garantir trabalho a todas as pessoas como condição à emancipação humana e à construção da dignidade e da igualdade entre as pessoas e no estabelecimento de relações harmônicas do ser humano com a natureza (MST, 2012, p.21). E para isto também precisa intervir de modo incisivo na educação deste trabalhador.

Para aprofundar esta questão vamos buscar em Gramsci, que em sua experiência com os operários das fábricas de Turim (1920), encontra nas comissões de fábrica os elementos que ajudam os operários a se compreender no processo produtivo e politico, isto é, elementos que estimulem o pensamento e a ação nos operários: dominar todo o processo produtivo até a comercialização e o exercício do poder político, na forma organizativa da fábrica, a participação nos processo de decisão. Isto leva o operário a se perceber como classe e a assumir os problemas de sua classe.

A escola do trabalho do L'Ordine Nuovo não tinha a intenção de preparar os trabalhadores para um mundo a eles estranho. Pelo contrário, a ideia era de reforçar o princípio da solidariedade e de saber fazer que era próprio de seu cotidiano de produtores, de incorporar o aprendizado já adquirido no espaço público gerado pela greve, pelo comício, pelo debate. O primeiro passo é , portanto, o de aceitar que o educador se deixe educar. O método, a disciplina e a solidariedade próprios do mundo da fábrica deveriam ser a base da escola do trabalho. (ROIO, apud, SOUZA JUNIOR, 2011).

O trabalho é aqui entendido como condição de emancipação humana, é direito e dever e por isso mesmo criador de igualdade social e de novas relações na sociedade, uma sociedade baseada no trabalho, onde todos terão que trabalhar para sobreviver.

E para alcançar estas mudanças a Reforma Agrária a que se propõe afirma sete grandes objetivos, vejamos:

- Eliminar a pobreza do campo;

- Combater a desigualdade social, todas as forma de exploração dos camponeses e a degradação da natureza que tem suas raízes na concentração da propriedade e da produção do campo;

- Garantir trabalho e educação para todas as pessoas que vivem no campo, combinado com a distribuição de renda; 
- Garantir a soberania alimentar a toda a população brasileira, produzindo todos os alimentos necessários com qualidade e desenvolvendo mercados locais;

- Garantir a participação igualitária das mulheres que vivem no campo em todas as atividades, em especial no acesso a terra, na produção e gestão, buscando superar a opressão histórica imposta às mulheres;

- Preservar a biodiversidade vegetal, animal e cultural da cada região do Brasil, e que formam nossos distintos biomas;

- Garantir condições de melhoria de vida para todas as pessoas e oportunidades iguais de trabalho, renda, educação, Saúde, moradia e lazer, estimulando a permanência no campo, em especial a juventude (MST,2012 p.23).

Como vimos a proposta de Reforma Agrária Popular defendida pelo MST, reflete os anseios de uma sociedade onde todas as relações terão que ser transformadas, desde as estruturais, aquelas que mexem com a estrutura do sistema que é a propriedade, a estrutura da produção no campo e as relações dos seres humanos com a natureza, com a terra com a vida e com os outros seres humanos.

Defende também um novo modelo tecnológico para a agricultura baseado na agroecologia e para que esse modelo possa ser implantado é necessário programas massivos de formação criando e envolvendo as escolas, universidades nesta tarefa. Aí pressupõe o desenvolvimento de campos experimentais, pesquisa participativa, intercâmbio entre agricultores; programa popular de agro biodiversidade e programa florestal.

$\mathrm{O}$ acesso à educação como uma necessidade para que se possa implementar a Reforma Agrária Popular tanto no sentido da "escolarização ampla como a de bens e valores culturais, como condição necessária para uma Reforma Agrária e para a democratização da sociedade" (MST, 2012, p. 26). Defende ainda uma educação que vai para além da escola, vinculada a um novo projeto de desenvolvimento econômico, social e ecológico para o campo. E os sujeitos desta educação são as pessoas que vivem no campo.

Trata a educação como um direito. O campo para se desenvolver precisa de cidadãos alfabetizados e escolarizados. E a formação técnica e profissional de nível médio e superior deve ser oferecida de forma a garantir o acesso e a permanência dos camponeses nos cursos sem perder seu vínculo com a terra e seu trabalho, e daí a importância dos cursos em alternância.

Também destaca a necessidade da formação de professores para atuar nas escolas do campo: garantir a formação em licenciatura de educadores nas universidades públicas, para atuação nas escolas públicas das áreas de reforma agrária através de políticas específicas e massivas de formação continuada e de alternância, para escolarização de nível médio e superior ( MST, 2012, p. 26).

O programa de Reforma Agrária Popular defende ainda as escolas nas comunidades com toda a infraestrutura necessária incluindo as escolas para as artes, o teatro, bem como espaços para práticas de produção agroecológica, hortas, pomares, para pesquisa e estudo.

Podemos entender que este programa defendido pelo MST que busca uma nova relação com a terra, as águas, com a vida e a natureza, incluindo as agroindústrias, exige também um novo homem e uma nova mulher e que a escola e a sociedade tem a obrigação de formar.

Ser educado como trabalhador neste contexto requer sim uma formação técnica/tecnológica que lhe permita participar dos processos produtivos do campo, construindo alternativas de trabalho e formas de produção que garantam sua sobrevivência, como pessoa, como grupo social... requer capacidade de leitura crítica da realidade...Exige fundamentalmente, que este trabalhador tenha / se forme em valores e convicções político ideológicas que o comprometam e fortaleçam na luta pelo trabalho, compreendendo-a como uma luta de sua classe contra o capital e tendo como referência um outro projeto de sociedade....(ITERRA, 2007, p. 186). 
O que está proposto no projeto de Reforma Agrária Popular na sua totalidade não é possível ser viabilizado nos marcos do capitalismo, exige pelo menos um governo popular, mas parte dele é possível ir implementando desde já. Por isso o MST forçado pela necessidade de fazer as terras conquistadas produzir e assim ir melhorando as condições de vida e de dignidade das famílias busca organizar cursos de formação profissionalizante para seus membros, primeiro forma seus educadores/as nos cursos de Magistério, depois os Técnicos para atuarem e serem os educadores da Cooperação: Técnico em Administração de Cooperativas; Técnico em Agroecologia; Técnico em Comunicação; Técnico em Agroecologia, Técnico em Saúde Ambiental entre outros. Todos os cursos que formam educadores que atuam dentro dos assentamentos. Estes cursos em parcerias com universidades e Escolas Técnicas através do Programa Nacional de Educação na Reforma Agrária (PRONERA).

Com a Reforma Agrária o Sem Terra retorna à terra e resgata o conhecimento, e agora neste novo estágio precisa organizar a produção e o trabalho, mas com o desenvolvimento do campo e da indústria não pode mais organizar o trabalho de forma artesanal, a realidade exige uma organização mais complexa, tecnologias adequadas a seus fins ou seja, produção de alimentos sadios, agroecologia, cooperação, se relacionar dentro de um território, organização da vida em sociedade, enfim exige conhecimentos mais complexos e especializados.

As práticas do MST e sua entrada no debate sobre educação profissional acontecem e devem ser interpretadas desde a materialidade específica do trabalho nas áreas de Reforma Agrária, neste momento histórico de desenvolvimento do capitalismo no Brasil e dos seus desafios concretos que a opção política por determinado projeto de campo coloca para a formação dos trabalhadores. (ITERRA, 2007, p.182).

Para hoje não vale mais o dito popular: "para trabalhar na roça não é preciso estudar". $\mathrm{O}$ trabalho do campo hoje exige estudo, qualificação, conhecer a terra, a natureza e como trabalhar com ela, mas também as relações com a sociedade. A produção de alimentos se dá em diferentes relações, exige o uso de tecnologia, que tem consequências. Que tecnologia usar e que consequências ela terá para a natureza, para as pessoas que a utilizam e para quem consome aquele determinado produto (alimento)? Como saber isto senão pelo estudo, pelo conhecimento, pela pesquisa.

O Sem Terra, como faz parte de um movimento social que teve acesso (ainda que parcial) à terra pela organização e no enfrentamento com o capital sabe que só conseguirá permanecer na terra se continuar organizado, com uma coletividade forte que mantenha o assentamento unido, "que seja capacitado a transformar uma leitura da realidade em organização para a ação coletiva"(ITERRA, 2007.p.186). Para isso, o campo precisa de escolas em seus territórios que permitam a todas as crianças, jovens e adultos o acesso a todos os níveis e modalidades de ensino.

E é esta realidade de exclusão e de necessidade, que leva o MST a se preocupar em buscar formas de acesso ao conhecimento a seus membros e a todos os trabalhadores do campo e quando o Estado não garantiu este acesso buscou estabelecer em seus espaços escolas, cursos que respondam a estas necessidades. No entanto, tem claro que só o Estado pode universalizar o direito à Educação e por isso não deixou de permanentemente fazer a luta por políticas públicas em educação do e no campo.

A partir dos seminários de educação realizados, vamos analisar o caminho que o MST vem fazendo neste sentido. É interessante observar que a primeira preocupação do MST não é com a formação de professores, mas com a necessidade de escolas nos assentamentos, a luta pelo direito. Os documentos dos seminários de 2005, 2006 e 2008 revelam isto. Estes seminários tiveram como foco as escolas dos assentamentos. Até 2005 são ainda, poucas as escolas nos assentamentos e menos ainda 
escolas básicas, ou seja, que ofereçam educação da Infância ao Ensino Médio, a maioria das escolas de assentamentos só oferecem educação da $1^{\mathrm{a}}$ a $4^{\mathrm{a}}$ série do Ensino fundamental. É um debate muito forte para compreender a função e o alcance das escolas de Ensino Médio, "debate sobre o acesso, mas também sobre concepção de educação", isto a partir de dois documentos base: o Boletim Especial da Educação, intitulado: "Educação Básica de Nível Médio nas áreas de Reforma Agrária" e o "Programa de Reforma Agrária Popular do MST" (Relatório, 2006).

E são os dados revelados pelo PNERA (Pesquisa Nacional de educação nas áreas de Reforma Agrária, 2004), que impactaram e ao mesmo tempo deram elementos científicos para o MST se voltar para analisar, compreender e buscar saídas que contribuam para elevar o nível de conhecimento que o atual estágio da Reforma Agrária, de implantação dos assentamentos e da luta de classes exige da classe trabalhadora. Segundo dados da pesquisa de 203 mil jovens existentes nos assentamentos na faixa de 15 à 17 anos, aproximadamente 47 mil estão fora da escola e dos que frequentam menos de 28 mil os que estão no ensino Médio...de um milhão e quatrocentos mil pessoas assentadas, apenas noventa e duas mil concluíram o ensino médio." (Relatório, 2006).

E é a partir desta realidade que o MST passa a pensar as escolas de Educação Básica: da infância ao Ensino Médio e "o que é básico na concepção de educação escolar" (2006) e afirma que educação é mais do que escola, diz respeito ao complexo processo de formação humana que acontece nas práticas sociais, mas a educação escolar é um componente fundamental neste processo, é um direito social e subjetivo de todos e um dever para os membros de uma organização com os objetivos que tem (Relatório, 2006).

O seminário também compreende um projeto de educação vinculado a um projeto político de transformação social, de classe e voltado a formação integral dos trabalhadores, e relacionado com a construção de um projeto popular para a agricultura brasileira articulado a um novo projeto de nação, soberana e justa, superando a dicotomia campo-cidade, compreendendo como dois espaços distintos, mas com estreitas relações de dependência.

As escolas podem ser "mais do que escolas" quando se constituem como uma referência sócio cultural para a comunidade: seja pelo envolvimento na solução de problemas locais e que permitem aos estudantes avançar no conhecimento científico, na apropriação de tecnologias e na capacidade de intervenção concreta na realidade, seja pelas oportunidades de vivência social que oferece, pelo recuperar a memória das famílias, ou pela oportunidade de contato com livros, filmes, debates expressões culturais diversas (Relatório, 2006).

É importante observar que já em 2006, há uma preocupação em vincular a escola às questões concretas do desenvolvimento do campo que não se confunda com uma visão estreita e pragmática de educação que a coloque a serviço do mercado de trabalho, mas também esta escola não ser reduzida ao dia a dia dos assentamentos descuidando da formação integral e geral do ser humano e da busca permanente do acesso aos conhecimentos produzidos pela humanidade. E afirma os princípios pedagógicos em vista das transformações que devem ocorrer na escola:

A realidade como base na produção do conhecimento e o estudo como capacitação para a leitura crítica da realidade, formação de uma visão de mundo, emancipação intelectual e exercício de um exame reflexivo das diferentes dimensões da vida humana; b) educação para o trabalho e pelo trabalho; c) participação nos processos de gestão democrática que incluí o desafio de auto-organização dos estudantes e de construção de uma coletividade educadora; d) trabalho coletivo e formação permanente de educadores. (Relatório, 2006).

Neste mesmo documento afirma que a juventude das áreas de Reforma Agrária tem direito "à educação profissional através de cursos técnicos profissionais e, assim como de continuar sua profissionalização no nível superior (Idem, 2006) e volta a reafirmar no seminário de 2007: o acesso a cursos técnicos não deve bloquear a luta pela educação superior (ITERRA, 2007, p.194). Mas chama a atenção que os cursos devem ser organizados para atender a uma demanda concreta dos processos 
produtivos do assentamento ou da organização, mas isto não pode encolher a escola para atender apenas a um grupo, mas estar voltada para atender a toda a juventude do assentamento.

Já no seminário de Luziânia, novembro de 2007 o centro das preocupações está na formação dos educadores e para isso faz uma retrospectiva do trabalho implementado e é interessante observar o vínculo direto com os processos da luta por escolas nas áreas de assentamento:

A formação de educadores começou junto com a luta por escolas e esteve na própria constituição do setor de educação do MST, (...) quando educadores se reuniam para discutir suas práticas... na época uma escola diferente" (Relatório, 2007, p. 2).

Esta formação não está vinculada a cursos formais, mas reunia educadores de EJA , Educação Infantil e os próprios educadores responsáveis pelo acompanhamento político-pedagógico de cursos formais, é uma prática que acontece até hoje no MST com mais ou menos intencionalidade. O documento chama a atenção sobre o lugar destas iniciativas não escolares na estratégia de formação dos educadores do MST.

O primeiro curso formal, de formação de educadores do MST foi o "Curso Normal de Nível Médio", em 1990, através do Setor de Educação do MST do Rio Grande do Sul e da (Fundação de desenvolvimento e Pesquisa da Região Celeiro) FUNDEP. "O curso tinha como objetivo preparar professores do próprio MST para assumir formalmente o trabalho docente nas escolas de anos iniciais do ensino fundamental" (Idem, 2007), ou seja, garantir titulação aos professores que já lecionavam nas áreas de Reforma Agrária, mas não tinham título de docência.

Com o tempo houve uma ampliação dos objetivos, a combinação entre formação profissional e de educadores militantes do setor para o conjunto da organização; a ampliação do conceito de formação de educadores: professores de escola para Educadores de EJA, educadores para as Cirandas Infantis, coordenadores de trabalho de educação em âmbito local, regional, estadual e nacional, formadores de base. A partir daí este curso se espalhou por todo país, realizados em parceria com muitas escolas e universidades.

Da formação de educadores se avançou para os cursos superiores e o primeiro foi o de Pedagogia, batizado de Pedagogia da Terra, em 1998, turma nacional, em parceria com a, UNIJUÍ, no RS, com a seguinte estratégia: qualificação teórica, pedagógica dos responsáveis pelo setor nos estados; avançar na elaboração coletiva; a segunda era continuar a formação de professores de escola, conquistando mais espaço nas escolas de ensino fundamental completo, o que incluiu as áreas de conhecimento. (RELATÓRIO, 2007, p.3).

Em 2003 se iniciou uma especialização em Educação do Campo numa parceria ITERRAUNB, na estratégia de especialização/profissionalização, com objetivo de formar educadores para coordenar, acompanhar e fazer docência nos cursos formais e intervenção política e pedagógica no debate e na implementação do projeto de Educação do Campo desde a perspectiva do MST. Tanto os cursos superiores como as especializações em Educação do Campo se multiplicaram por todo o país.

A partir destas experiências outras iniciativas na área das Licenciaturas, em âmbito regional, estadual e nacional, foram se tornando uma realidade na perspectiva da Educação do Campo e sempre em alternância (Em Artes, Letras, Ciências Agrárias, História, e Geografia). Também houveram iniciativas em outras áreas do conhecimento como Direito, Veterinária, Agronomia, não sem contestações e conflitos com a ordem estabelecida. O Curso de Direito em parceria com a Universidade Federal de Goiás foi questionado na justiça sobre a sua validade até o momento da formatura da turma , em novembro de 2012, o Curso de Médico Veterinário, com a Universidade Federal de Pelotas foi questionado pelo Ministério Público e o vestibular ficou suspenso por dois anos, até o juiz dar ganho de causa aos trabalhadores inscritos, para poder iniciar as aulas. Os trabalhadores organizados conquistando o direito a educação superior é uma "subversão" à ordem, significa uma ameaça as "categorias" e a estabilidade da sociedade. 
Em 2006 se inicia o debate sobre a necessidade de uma licenciatura em Educação do Campo, o que se consolida em 2007 com a primeira turma no ITERRA- RS, em parceria com a UnB. "A estratégia a que este curso se vincula é a ampliação do número de escolas de ensino fundamental anos finais e ensino médio no próprio campo." (Relatório, 2007, p.4).

Alguns limites e tensões se observam nestes processos educativos como a diminuição pela procura para os cursos de magistério; conflito entre necessidade de formação da organização e o currículo oficial que deve ser seguido; base teórica do curso e a referência teórica do MST que é o Materialismo Histórico Dialético (em muitas universidades é o paradigma pós-moderno); no acompanhamento político pedagógico; registros, elaboração das experiências; acompanhamento Trabalho de Conclusão de Curso; respeito a diversidade e unidade nos cursos. Isto demanda avaliação, debate das demandas e estratégias dos cursos.

Os cursos formais nasceram vinculados a estratégia e para atender a demandas concretas da organização. Os Cursos formais não podem ser tratados como "cursos escolares, e particularmente os técnicos profissionais, como se eles fossem a solução dos problemas dos assentamentos e da organização como um todo; como se fossem a estratégia e não uma ferramenta (tática) para implementá-la ou mesmo para construí-la coletivamente. (ITERRA, 2007, p.186 ).

Isto leva a reflexão de que os cursos estão vinculados a uma "Estratégia Política maior do MST de formação de militantes, continuadores da luta e da organização coletiva" (2007, p.6). Esta coloca exigências específicas de formação relacionadas a dimensões a serem trabalhadas como a formação ética, consolidação de valores, a formação político ideológica que passa pelo referencial marxista de análise, pela vivência dos princípios e da mística da organização, a pertença à classe, a capacitação nas habilidades relacionadas à organização, método de direção, de estudo, da pesquisa, da pedagogia de trabalho com o povo. Os cursos não conseguirão atender ao todo destes desafios, mas terão que dar suporte à formação nesta perspectiva.

Ao mesmo tempo não podemos perder de vista a que esses cursos vieram. Está preparando para que trabalho específico e no caso a formação de educadores deve primar por preparar educadores para garantir a "universalização" do acesso dos camponeses à educação (escolar básica), que inclui Educação Infantil, Ensino Fundamental e Ensino Médio, também na modalidade de jovens e adultos, formar educadores capazes de ocupar e coordenar as escolas públicas que temos em nossas áreas, de conduzir processos educativos escolares, em cada uma das etapas da educação básica, de exercer docência em sala de aula e de organizar as comunidades para lutar para que o número destas escolas se amplie, formação de educadores populares; preparação de militantes para o trabalho político pedagógico.(Relatório, 2007, p.7).

A formação de educadores deve incluir três dimensões fundamentais: 1) os aprendizados básicos - nível escolar; 2) a formação geral e específica voltada a estratégia da formação da militância; 3) a formação profissional para o trabalho.

Além da intencionalidade pedagógica para o trabalho específico não se pode perder de vista a estratégia da organização, a concepção dos cursos não pode estar atrelado simplesmente a profissionalização estreita, por mais que seja pertinente e qualificada que possa ser.

Formar o educador que saiba juntar teoria e prática em um mesmo movimento que é de transformação do mundo e de autotransformação humana, de modo que possa ajudar a desencadeá-lo nos processos educativos que acompanha (Relatório, 2007, p.10).

A entrada do MST no debate sobre formação profissional aconteceu e deve ser interpretado desde a materialidade da luta por Reforma Agrária e do trabalho nos assentamentos no atual momento histórico onde o capitalismo se expandiu no campo e não tem necessidade da agricultura camponesa e da Reforma Agrária para se expandir e alcançar seus objetivos. 
Discutir hoje no Brasil o tema da educação profissional desde a realidade das áreas de Reforma Agrária é uma dupla subversão da ordem estabelecida: porque a Reforma Agrária está sendo considerada um obstáculo ao pleno desenvolvimento do capital no campo (vista como retorno da arcaica agricultura camponesa diante da pomposa modernidade do agronegócio) e porque a própria expressão "educação profissional" é representativa de um tipo de política educacional não pensada para estes sujeitos e para a perspectiva de projeto de campo." (ITERRA, 2007, p. 182)

E neste sentido no seminário de 2008, volta a preocupação com a escola do e no assentamento, defende as Escola Públicas e convoca a todos educadores, educandos, cada comunidade, em cada local a entrar nesta "empreitada" para ocupar a escola ajudando "na apropriação da escola pela classe trabalhadora e seu projeto histórico" (Relatório, 2008).

Manacorda chama a atenção sobre o pensamento de Gramsci quando observa, "a participação realmente ativa do aluno na escola somente pode existir se a escola estiver ligada à vida; para ele a relação não se dá entre indivíduos singulares, mas sempre entre indivíduos que representam todo complexo social" (Idem, 2010, p.150).

Chama a atenção para outra forma escolar, pois a atual garante a educação para o capital, para manter a ordem estabelecida. É necessário alterar as relações de poder dentro da escola e para isso transformar as formas organizativas, a gestão da escola. A auto-organização dos estudantes deve ser estimulada.

O trabalho na escola é outro aspecto que perpassa todo o debate sobre educação e escola no MST. A escola que conhecemos foi desenhada para separar o saber e o fazer e por isso sua centralidade absoluta está na sala de aula.

Estamos tratando de algo mais radical, complexo, que é de tornar o trabalho a base integradora do projeto formativo da escola, vinculando os conhecimentos escolares ao mundo do trabalho, da produção, da cultura que o trabalho produz. (Relatório, 2008, Seminário MST e a Escola).

A questão do princípio educativo do trabalho precisa ser debatida, estudada a partir das práticas educativas e da teoria. $\mathrm{O}$ trabalho socialmente necessário é fundamental na formação do trabalhador, pois "não podemos criar em nosso meio mamíferos de luxo". Lutamos por uma sociedade onde todos trabalhem para viver.

Os princípios filosóficos e pedagógicos da educação do MST necessitam ser aprofundados no seu entendimento em cada momento da história à luz das teorias que os embasam: a realidade como base para o estudo e o conhecimento; a inserção da escola nas lutas sociais e suas organizações coletivas; trabalhar a formação do ser humano nas suas diferentes dimensões.

Ao debater a formação profissional não está falando na formação de profissionais para o mercado, mas muito mais da apropriação pelos trabalhadores de conhecimentos e habilidades necessárias para o desempenho de funções que o integrem nos processos produtivos próprios, de compreensão de como e porque, e que consequências tem para a sociedade e para a vida fazer ou deixar de fazer determinada ação, ler a realidade e intervir na organização da classe, na preparação de lutadores e construtores, de educadores de sala de aula, mas também educadores na produção, na saúde, na organização de base. Tudo isto nos remete a voltar para as propostas de Marx nas instruções aos delegados do I Congresso da Associação dos Trabalhadores, em Genebra (1866), sobre o conteúdo do ensino pedagógico socialista:

Por ensino entendemos três coisas: primeira, ensino intelectual; segunda, educação física, dada nas escolas e através de exercícios militares; terceira, adestramento tecnológico, que transmita os fundamentos científicos gerais de todos os processos de produção e que, ao mesmo tempo, introduza a criança e o adolescente no uso prático e na capacidade de manejar os instrumentos elementares de todos os ofícios. (MARX apud MANACORDA, 2010, p.48). 
Em maio de 2007, o MST realiza um seminário da Região Sul, promovido pelo Instituto Técnico de Capacitação e Pesquisa da Reforma Agrária (Iterra), com o objetivo de avaliar, estudar e debater sobre as experiências em Educação Profissional e Reforma Agrária. Este seminário revela que o MST tem outra concepção de educação ou formação profissional daquela concebida pelo Estado. Para o Estado formação profissional é capacitar o trabalhador para se inserir no mercado, para simplesmente responder às necessidades do mercado. O MST quando fala e quando faz a formação profissional o faz sob outros princípios, ou seja, responder a necessidades específicas do assentamento ou da organização: "O TAC (Curso Técnico em Administração de Cooperativas) sempre esteve estreitamente ligado ao desenvolvimento das discussões e práticas de cooperação dos assentamentos". (ITERRA, 2007, p.71), mas também vinculados a uma estratégia de formação humana omnilateral e de construção de uma nova sociedade: o método do Instituto possibilita lapidar a visão de mundo dos educandos, desenvolvendo perspectivas mais críticas e fundamentais para a formação geral, que se sabe fazer muita diferença na atuação profissional (ITERRA, 2007, p.63).

Neste seminário de avaliação de 2007 o Iterra foi incisivo em suas avaliações sobre o seu método de trabalho e de organização das turmas para atingir aos objetivos a que se propôs, e ao analisar o curso do TAC considerou aspectos metodológicos que considerou fundamentais neste curso como: O regime de alternância; a busca de capacitação organizacional a partir de experiências reais de organização durante o curso; o desenvolvimento de experiências reais; trabalho como elemento pedagógico; influência do setor de produção na concepção do curso; o repasse e gestão autônoma dos cursos pelos educandos; a participação dos educandos na cogestão das atividades educativas e pedagógicas do instituto e do curso; relação com o mercado como elemento pedagógico (ITERRA, 2007, p.102).

Se educa para dirigir, gerenciar garantindo espaços reais de gestão e não de "faz de conta", e "os estudantes passaram a ter nas mãos uma empresa econômica e pedagógica real que devia ser gerida com total autonomia pelos estudantes, desde que respeitassem os princípios do curso e da entidade promotora". (Iterra, 2007, p.103).

O entendimento de educação profissional desenvolvido pelo MST se aproxima mais de uma compreensão de politecnia desenvolvida desde toda a educação básica "Trata-se muito mais de qualificar a educação básica, para que a formação geral que lhe é própria se faça de modo integrado ao mundo do trabalho, da produção, da cultura, da ciência, da luta social" (ITERRA, 2007, p.195).

a Educação Profissional do Campo precisa refletir sobre como se garante no currículo dos cursos o vínculo entre conhecimento e prática de trabalho, buscando superar a cisão entre trabalho manual e trabalho intelectual; sobre como se combina capacitação técnica com domínio científico e tecnológico dos processos produtivos em que esta área de trabalho se insere.”(ITERRA, 2007, p.199)

A luta pela universalização da educação em todos os níveis e modalidades, mas chama a atenção para o direito a Educação Básica de qualidade e para todos nos locais onde vivem. Esta questão foi tema de debate no Seminário Nacional:" Juventude e Ensino Médio nos Assentamentos de Reforma Agrária”, em Guararema, SP, de 19 a 23 de março de 2013 onde, mais uma vez ficou claro que, a luta do MST pelo direito ao Ensino Médio para toda a juventude dos assentamentos está inserida em uma luta maior por Educação Básica de qualidade nos locais onde vivem.

Aprofundando o entendimento sobre politecnia no Seminário "Educação politécnica e Agricultura Camponesa", realizado em Veranópolis, 14 a 16 de março 2012 reconhece sua pertinência para a educação nas áreas de Reforma Agrária neste momento histórico.

A situação objetiva nos impõe como prioridade resistir ("lutamos para não morrer") e nossa estratégia nos exige resistir projetando e construindo o futuro, isso vale para a produção como para a educação... Nossa juventude precisa ser preparada para o trabalho necessário e na perspectiva de sua emancipação humana. Isso é fundamental na formação da geração de trabalhadores para a luta social e 
para assumir o comando da produção social. Talvez a perspectiva da formação politécnica seja um caminho para que se trabalhe estes desafios como síntese. (Relatório, 2012).

Para entender a politecnia o seminário revisita os autores marxistas e pedagogos socialistas como Marx, Lenin, Krupskaia, Pistrak, Shulgin, entre outros, considerando a atual realidade da agricultura, de campo os embates e enfrentamentos na luta pela Reforma Agrária e a necessidade de formação dos camponeses neste contexto.

Em Shulgin encontra novas categorias como politecnismo e trabalho socialmente necessário, as quais destaco abaixo:

O politecnismo (levantou-se a hipótese sobre a diferença deste termo e o de politecnia) como um sistema completo de conexão da educação com o trabalho, envolvendo atividades para todas as idades e incluindo, a partir de certa idade o trabalho produtivo mais complexo ( no caso da época, e por inspiração direta de Marx, na fábrica); algo que a escola precisa assumir, mas que não se restringe à relação com ela; há politecnismo fora da escola: há um ambiente social a ser qualificado nessa perspectiva; - o conceito de trabalho socialmente necessário é contribuição teórica específica de Shulgin no debate do trabalho como base da educação e da reeducação das pessoas; é o trabalho real, necessário e por isso pedagogicamente valioso; inclui o trabalho produtivo, mas não se reduz a ele; este é o conceito de trabalho que está na base do politecnismo (talvez o produtivo como base da politecnia, propriamente dita, uma hipótese a verificar em estudos mais aprofundados dos textos de Shulgin e de Pistrak); - coloca no politecnismo a dupla exigência: de superação da separação entre trabalho manual e trabalho intelectual, mas também a superação do fosso entre cidade e campo...Shulgin destaca como característica fundamental da politecnia o conhecimento dos princípios básicos de todos os processos de produção, do trabalho substancial em algumas indústrias, dos postos de trabaho que tornem possível obter algumas habilidades práticas; - a entrada do politecnismo se dá pelo trabalho e não pela técnica ou tecnologia em si; distingue a formação politécnica da formação profissional( Relatório, 2012).

Politecnia, politecnismo e trabalho socialmente necessário são questões que estão postas para discussão, debate, aprofundamento teórico e experimentação na prática, como o MST é um Movimento Social tudo isto de alguma forma já está se realizando na prática pedagógica, principalmente nas escolas que tem um vínculo orgânico e de formação com o MST, a materialidade histórica está exigindo uma postura pedagógica cada vez mais consequente com as estratégias a que o Movimento se propõe.

E na crítica a escola pública, à educação básica oferecida pelo Estado, muitas vezes, nos conformamos em achar que é muito difícil fazer mudanças na mesma e assim deixamos de perceber a força das contradições que existem nesta escola. Se existem contradições há movimento, e se há movimento é possível subverter a ordem dada. E para isso aprofundar o entendimento de escola pública. Pública, compreendida como conduzida pelo povo, do povo, da comunidade e não escola do "governo", do Estado. O assentamento dentro da escola e a escola dentro do assentamento, uma escola financiada pelo Estado e conduzida pela comunidade.

Para que a comunidade, o assentamento possa estar dentro da escola intervindo é necessário prepará-lo. As famílias, as lideranças precisam ter conhecimento teórico e prático dos desdobramentos pedagógicos das teorias da educação que direcionam os processos educativos dentro da escola, das políticas de governo, da natureza do Estado, da força da comunidade e do povo organizado, só assim poderão intervir com capacidade e qualidade, trabalhando as contradições existentes e transformando em ações educativas da classe trabalhadora.

A classe trabalhadora mesmo não tendo tido o acesso à universidade tem capacidade de acessar e produzir conhecimento a partir de outra perspectiva que é da prática do trabalho e da vida. E são estes elementos que levam o MST a se atrever a propor e a experimentar outra forma de fazer 
escola, trazendo esta realidade para dentro da mesma. Trabalho, luta social, história, organização e cultura são as matrizes pedagógicas fundamentais na sua pedagogia.

E a educação profissional é uma necessidade inerente a sua prática social desde a sua origem. No início de sua prática pedagógica, mesmo não tendo ainda conhecimento dos clássicos da educação marxista o MST defende posições dos mesmos e vai aperfeiçoando na medida em que vai buscando na teoria elementos para fortalecer e dar consistência a sua prática. Em nenhum momento aparece a formação profissional como preparação para o mercado, mas quer formar trabalhadores, organizadores e lutadores. E a base para esta formação é o trabalho real, concreto.

Para o camponês, o Sem Terra, lutar pela terra nada mais é do que lutar pelo direito de trabalhar, pelo direito de manter a sua dignidade humana e se desenvolver, por isso terra é trabalho, organização, cultura, história e luta. Voltando a Marx, quando está preocupado com a educação das crianças, defende o trabalho como um dos fatores de seu desenvolvimento humano é necessário que seja estimulada em todos os aspectos, seu corpo, sua mente, sua capacidade de se organizar e de criar e a defesa de uma sociedade sem classes vem no sentido de que o ser humano precisa tempo livre para criar e usufruir dos bens que produziu. Em a Ideologia Alemã Marx, defende a necessidade do desenvolvimento real das forças produtivas como condição material e preliminar para a supressão da propriedade privada e a completa emancipação de todos os sentidos e de todas as qualidades humanas e se instalar o reino da liberdade.

Nesta perspectiva vislumbramos muitas possibilidades de uma escola de assentamento onde as crianças possam desenvolver todas as suas dimensões humanas dadas a materialidade histórica: ser o assentamento fruto de uma luta coletiva, a sua organicidade interna, é um espaço onde se vive e se reproduz a VIDA individual e coletiva, o sonho e a realidade se encontram e se desencontram. Mas não é uma ilha, também ali a força do capital se impõem e coloca limites a uma escola que não segue os seus padrões de educação. Impõem limites a forma de organizar o assentamento e a produção, o trabalho, o fetiche da mercadoria, do lucro, do individualismo imposto pelo capital também atinge a família assentada, há contradições, mas também há possibilidades.

Mesmo com estes limites a politecnia em uma escola de assentamento é uma possibilidade concreta. $\mathrm{O}$ estudo e a prática das tecnologias na agricultura, suas finalidades e consequências na vida, na saúde das pessoas e na sociedade. Desde a infância é possível ir introduzindo as relações do trabalho humano, as reações da natureza. O que é da natureza o que é criado pela ação humana e num crescendo até chegar aos anos finais do Ensino Fundamental e no Ensino Médio à prática e o estudo aprofundado dos diferentes modelos de agricultura, a experimentação e pesquisa de novas práticas. $\mathrm{O}$ conhecimento das mais avançadas tecnologias (OGM, nanotecnologia...) e suas consequências. A experimentação da administração, da comercialização dos produtos (mercado), mas também a cooperação, a agroecologia, a luta pela Reforma Agrária. Todas estas práticas e teorias integradas a vida do assentamento. Neste sentido, a escola pode contribuir com a sua parcela na formação de lutadores e construtores, mesmo sabendo que sozinha não dará conta, que o assentamento precisa também trabalhar na mesma direção.

Os limites e as dificuldades não podem deter o "sonho" de uma sociedade sem classes onde todos os seres humanos possam desenvolver todas as suas potencialidades se compreendendo no universo e então viver "o reino da liberdade". 


\section{REFERÊNCIAS}

CALDART, Roseli Salete, PEREIRA; Isabel Brasil, ALENTEJANO; Paulo, FRIGOTTO; Gaudêncio (orgs). Dicionário da Educação do Campo. Rio de Janeiro: São Paulo, EPSJV, Ed. Expressão Popular, 2012.

CALDART, Roseli Salete. Relatório-síntese do Seminário: "Educação e Politécnica e Agricultura Camponesa”, Veranópolis,RS, IEJC, 2012.

CALDART, Roseli Salete; Maria Nalva Araújo; Edgar Jorge Koling. Sobre o Seminário "Formação de Educadores nos Cursos Formais. Luziânia, GO, novembro de 2007.

Documento Final do $1^{\circ}$ Seminário Nacional "Caminhos da Educação Básica de Nível Médio para Juventude das áreas de Reforma Agrária”, Luziânia, setembro de 2006.

FRIGOTTO,Gaudêncio, CIAVATTA,Maria, RAMOS,Marise, O Trabalho Como Princípio Educativo no Projeto de Educação Integral de Trabalhadores, extraído do livro: Educação Integral e Sistemas de Reconhecimento e Certificação Educacional e Profissional,Org.COSTA, Hélio da conceição, Martinho da, São Paulo; CUT, 2005.

ITERRA ,Cadernos do, ano VII, $\mathrm{n}^{\circ}$ 13, O Intituto Josué de Castro e a Educação Profissional, Veranópolis, RS, 2007

KOLING, Edgar Jorge, Roseli S. Caldart, Sandra L. Dalmagro. Relatório: Sobre o Seminário, "O MST e a Escola". Brasília, DF, junho 2008.

MANACORDA, Mario Alighiero. Marx e a Pedagogia Moderna. 2a edição, São Paulo: Ed. Alínea, 2010.

MARX, Karl, O Capital: crítica a economia política. Vol. 1. 29a edição, Rio de Janeiro: Ed. Civilização Brasileira, 2011.

MARX, Karl e ENGELS, Frederich . Obras Escolhidas. tomo III, Tradução Barata-Moura, José, Chitas, Eduardo, Malo, Francisco, Pina,Alvaro. Ed. Progresso Moscou, Ed. Avante! Lisboa, 1988.

MARX, Karl e ENGELS, Frederich. Manifesto do Partido Comunista. $1^{a}$ Edição. São Paulo: Ed. Expressão Popular, 2008.

Marx, Karl, Engels, Friedrich. A Ideologia Alemã. São Paulo:Ed. Expressão Popular, 2009.

MST. Documentos Básicos, 2012.

MENDONÇA, Sonia Regina de. Agronomia e Poder no Brasil. Rio de Janeiro: Vício de Leitura, 1998.

SAVIANI, Demerval. O Choque Teórico da Politecnia, art.,Rev. Trabalho Educação e Saúde, 2003.

SOUZA JUNIOR, Justino de. Marx e a crítica da Educação: Da expansão liberal-democrática à crise regressivo destrutiva do capital, $2^{\mathrm{a}}$ edição, São Paulo: Ed. Ideias \& Letras, 2011. 
THERRIEN, Jaques Damasceno, Maria N (org). Educação e Escola no Campo, Campinas: Papirus, 1993. 